\title{
Anterior and posterior nutcracker syndrome accompanying left circumaortic renal vein in an adolescent. Case report
}

\author{
Mehmet B. Özkan, M.D. ${ }^{a}$, Meltem Ceyhan Bilgici, M.D. ${ }^{a}$ and Emre Hayalioglu, M.D. ${ }^{a}$
}

\begin{abstract}
The left renal vein (LRV) has many developmental variations; the two most common are the circumaortic and the retrocaval. Anterior nutcracker syndrome is the compression of the LRV between the aorta and superior mesenteric artery, whereas posterior nutcracker syndrome occurs between the vertebral column and the aorta. An adolescent male (aged 16 years) was referred to the emergency department for flank pain. CT findings showed the combination of anterior and posterior nutcracker syndrome in the left circumaortic renal vein, which has not previously been described in an adolescent.

Key words: circumaortic renal vein, anterior-posterior nutcracker syndrome, adolescent, pediatrics, radiology.
\end{abstract}

http:/ /dx.doi.org/10.5546/aap.2016.eng.e114

\section{INTRODUCTION}

Left renal vein (LRV) anatomy has a complex embryogenesis. Developmental venous anomalies, includes circumaortic or retroaortic variants. ${ }^{1}$ Anterior nutcracker syndrome is defined as the compression of the LRV between the superior mesenteric artery (SMA) and the aorta, whereas posterior nutcracker sydrome is the term used to refer to the compression of the retroaortic LRV between the aorta and the vertebral column. ${ }^{2}$ It is extremely rare for circumaortic LRV to accompany both anterior and posterior nutcracker syndrome, and it has only previously been reported once in the literature, in a middle-aged woman. ${ }^{3}$ We present this feature in an adolescent male, within a brief review of the literature.

\section{CASE REPORT}

A male adolescent aged 16 years was brought to the emergency department because of left flank pain and tenderness. His flank pain was

a. Department of Pediatric Radiology Department. 19 Mayıs University, KurupelitKampusu, Samsun Turkey.

\section{E-mail Address:}

Mehmet B. Özkan, M.D.: Burakozkan79@hotmail.com

Funding: None.

Conflict of interest: None.

Received: 8-11-2015

Accepted: 10-19-2015 characteristically intermittent. He told us that he had suffered the pain two or three times per month. The pain had not a specific characteristic like a colic or organ issue specific variant. Pain was located in the left superior region. Blood pressure was 125/ $84 \mathrm{mmHg}$ which points out a bit high values for venous hypertension. However, he had no fever, hematuria, vomiting, or diarrhea, and no history of trauma. Urine examination was within normal limits and creatinine clearance value was $98 \mathrm{ml} / \mathrm{min}$. His height and weight values were within the normal percentage limits.

He had previously been diagnosed with familial mediterranean fever (FMF). To rule out the FMF a sonography was done. There were not any specific issue on the sonography. Neither free fluid nor solid organ involvement were seen. Absence of free fluid in the peritoneal spaces rule out a FMF episode. A computed tomography (CT) scan showed circumaortic LRV draining to the vena cava inferior. There was division of the LRV in the course near the descending aorta. The anterior superior branch was compressed between the SMA and the aorta. In addition, the posterior inferior branch showed entrapment between the aorta and the vertebral column. There was segmental bulbous dilatation, due to the compression (Figure 1a,b).

The patient had no hematuria and the spontaneous resolution of the pain in two days revealed out the need of a surgical treatment. The patient is pain free without any intermittent episodes within one and half year. Within this time, the patient 's control hypertension was 132/70 mmHg which was a bit still high.

\section{DISCUSSION}

The fetal LRV develops between the 4 th and 8 th gestational weeks. The duration of this developmental sequence is full of different complex mechanisms, including regression and rotation movements. During this process, abnormal development causes variations in the renal venous system. Failure in regression of posterior arc anastomosis causes circumaortic LRV. ${ }^{4}$ The two most common variants are those of the circumaortic and retroaortic left renal venous 
types. The median incidence of circumaortic LRV found in cadavers is $7.0 \%$, whereas the imaging modalities are $1-3 \%$ of the variations. ${ }^{5}$

In adults, CT with contrast is the preferred method for identifying renal vein variations, although it means exposure to a dose of radiation. ${ }^{4}$ However, there is no clear information regarding renal vein variations in children.

Most individual cases are found incidentally. It is important to be aware of these variants before a surgical procedure, which can lead to hemorhage of the dorsal vein. ${ }^{6}$ De Schepper described the entrapment of the LRV between the SMA and the aorta as anterior nutcracker syndrome. The posterior analog of the compression between the aorta and the vertebral column is known as posterior nutcracker syndrome. The term 'posterior nutcracker syndrome' refers to the left renal venous hypertension secondary to the compression of the retroaortic left renal vein, which crosses between the aorta and the vertebral column. ${ }^{3}$ Vertebral osteophytes can also cause posterior nutcracker syndrome, as defined by Rassi et al. ${ }^{7}$

The diagnostic criteria for anterior nutcracker syndrome is the angle between the aorta and the SMA, which has been reported as being $39.3^{\circ} \pm$ $4.3^{\circ}$, but can certainly be approximately $14.5^{\circ}$ at its lowest. ${ }^{8}$ In children, it was measured as being $17^{\circ}-57^{\circ}$, which was narrower than in the healthy group, but there is not a defined angle criteria for posterior nutcracker syndrome.
The gold standard method for diagnosis of nutcracker syndrome is retrograde phlebography and cine video-angiography with renocaval pressure gradient determination. Cine videoangiography with visualization shows the exact point of the entrapment of the LRV at the mesoaortic crossing level, and the retrograte contrast reflux to the adrenal and gonadal veins. ${ }^{8}$

Anterior and posterior nutcracker syndrome causes venous hypertension, and the presence of extra renal and intra renal venous collaterals, which could cause pelvic varicies and congestion syndrome.

The intrarenal pressure increasement due to the entrapment in the mesoaortic level produces a reflux towards the left ovarian/ testicular veins. These refluxes causes varicoceles in the testicular region. There is not an age specific correlation in the literature. Therefore in our case the pressure increasement in the left renal vein were not high enough to cause a collateral or varicocele in the testicular region. This could be due to the patient's age.

Hematuria is another common finding in serious left flank pain. Alaygutet al. ${ }^{9}$ showed that proteinuria is the most common symptom accompanying hematuria in children.

Various methods have been described in the treatment of nutcracker syndrome, and endovascular treatment is the first line of therapy in adults. ${ }^{10}$ In pediatric age group, transposition of LRV was described as a novel

Figure 1. Maximum intensity projection image reconstruction from CT images shows a, the anterior superior branch compressed between the superior mesenteric artery and the aorta (arrowhead), $\boldsymbol{b}$, the posterior inferior branch shows entrapment between the aorta and the vertebral column (arrow). There is segmental bulbous dilatation in both, due to the compression.
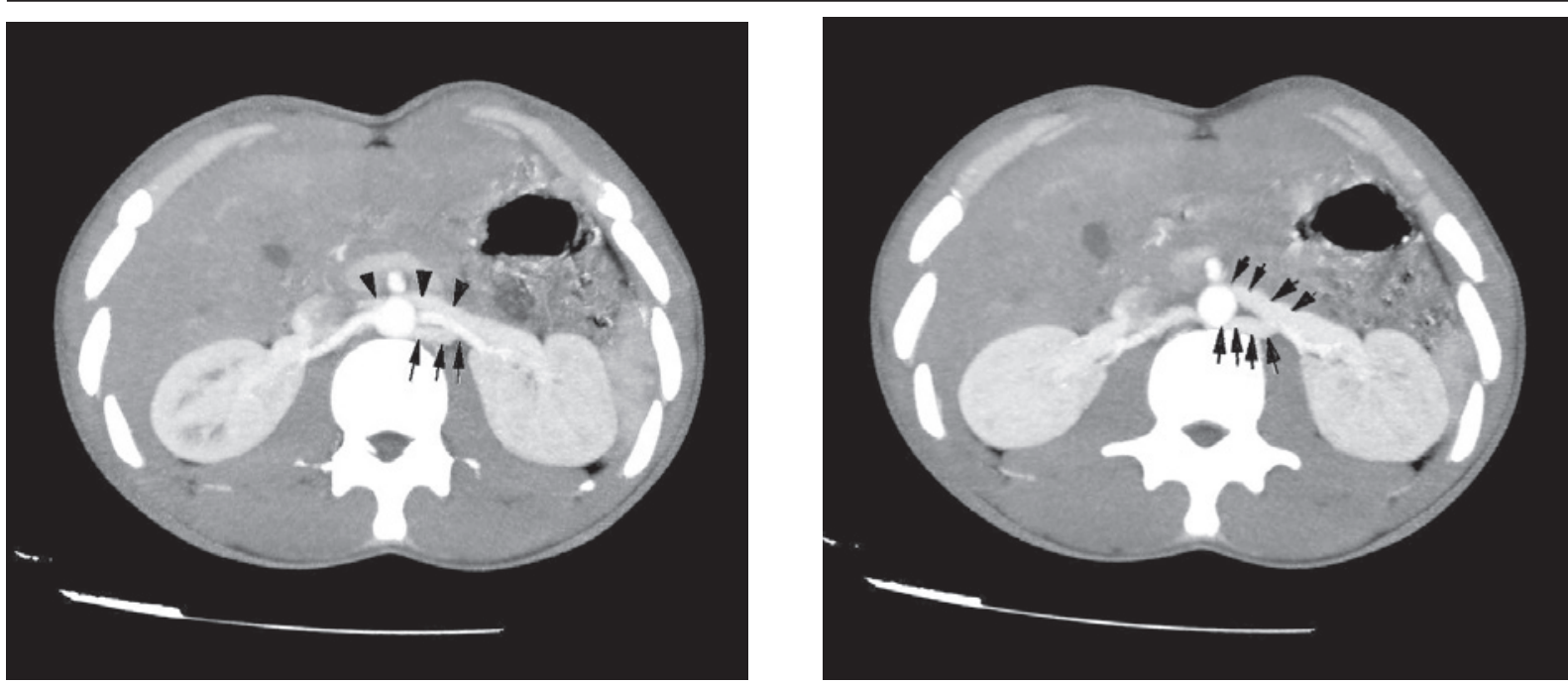
surgical procedure. ${ }^{11}$ In our patient there were not a hematuria and additionally a varicocele did not occur. There was an intermittent pain complianment. There were dilatation of anterior and posterior components of the renal vein. The cases which went under surgical or interventional treatment had hematuria or pelvic congestion syndrome..$^{8-11}$ The association of anterior and posterior nutcracker phenomene with the circumaortic LRV has only previously been described in the English literature on one occasion, in a middle-aged woman. ${ }^{3}$

To the best of our knowledge, this is the first case described in an adolescent age patient group in the literature.

\section{CONCLUSION}

LRV variants should be considered in the differantial diagnosis of left flank pain with hematuria. The exact details of the venous anatomy must be reported by the radiologist, as these can explain the cause of the pain, with no need for further diagnostic tests.

\section{REFERENCES}

1. Yi SQ, Ueno Y, Naito M, Ozaki N, et al. The three most common variations of the left renal vein: a review and meta-analysis. Surg Radiol Anat 2012;34(9):799-804.
2. Ali-El-Dein B, Osman Y, Shehab El-Din AB, El-Diasty T, et a. Anterior and posterior nutcracker syndrome: a report on 11 cases. Transplant Proc 2003;35(02):851-3.

3. De Visschere P, De Man R, Rosseel F, Crolla D, et al. Combined anterior and posterior nutcracker phenomenon in circumaortic left renal vein [Internet]. Vienna: EuroRad; 2008 Nov 12. [Accessed: 2015 Oct 22]. Available from: http:/ / www.eurorad.org/ case.php?id=6962

4. Dilli A, Ayaz UY, Kaplano lu H, Saltas H, et al. Evaluation of the left renal vein variations and inferior vena cava variations by means of helical computed tomography. Clin Imaging 2013;37(3):530-5.

5. Zhu J, Zhang L, Yang Z, Zhou H, et al. Classification of the renal vein variations: a study with multidetector computed tomography. Surg Radiol Anat 2015;37(6):667-75.

6. Resorlu M, Sariyildirim A, Resorlu B, Sancak EB, et al. Association of congenital left renal vein anomalies and unexplained hematuria: multidetector computed tomography findings. Urol Int 2015;94(2):177-80.

7. Rassi I, Khabbaz Z, Chelala D, Jebara VA. A new variant of the posterior nutcracker phenomenon. J Vasc Surg 2010;51(5):1279.

8. Inal M,Karadeniz Bilgili MY, SahinS. Nutcracker syndrome accompanying pelvic congestion syndrome; color doppler sonography and multislice CT findings: a case report. Iran J Radiol 2014;11(2):e11075.

9. Alaygut D, Bayram M, Soylu A, Cakmakc1 H, et al. Clinical course of children with nutcracker syndrome. Urology 2013;82(3):686-90.

10. Liu Y, Sun Y, Wu XJ, Jiang Y, et al. Endovascular stent placement for the treatment of nutcracker syndrome. Int Urol Nephrol 2012;44(4):1097-100.

11. Reed NR, Kalra M, Bower TC, Vrtiska TJ, et al. Left renal vein transposition for nutcracker syndrome. J Vasc Surg 2009;49(2):386-93. 